\title{
Galeazzi Fracture-Dislocation Concomitantly With Radial Head Fracture, A Case Report and Suggest the Mechanism of Production of This Rare Injury
}

\author{
Alberto Izquierdo Fernández*, Maria del Carmen Ruiz Bonilla, Rafael Carlos Muñoz Lópe and José Carlos Díaz \\ Miñarro
}

Department of Traumatology and Orthopedic Surgery, Reina Sofía University Hospital, Spain

Submission: May 29, 2018; Published: June 20, 2018

*Corresponding author: Alberto Izquierdo Fernandez, Department of Traumatology and Orthopedic Surgery Hospital Universitario Reina Sofia, Av Menendez Pidal sn Zip code: 14004, Cordoba, Spain, Tel: (+34) 667789977; Email: alberto.izquierdo.fer@hotmail.com

\section{Abstract}

Galeazzi fracture-dislocations and radial head fractures are not exceptional lesions separately. However, the association between those conditions is extremely unusual. This is the second case reported in literature depicting a Galeazzi fracture-dislocation and radial head fracture concomitantly. We present a case and suggest the mechanism of production of this rare injury.

Keywords: Galeazzi fracture; Radial head; Internal fixation

\section{Introduction}

The high-energy trauma can cause rare injury. The association described here has been reported only at once time. In this paper we present a case and propose a mechanism of injury that may explain the presence of both fractures.

\section{Case Presentation}

We report the case of a 47 years old man who arrived at our emergency room following a motorbike accident complaining about local tenderness and deformity in his right forearm and elbow. No elbow instability was found. Loss of function was presented in his right elbow and wrist as well. No initial

neurovascular alterations were found through examination. The patient did not mention any prior medical history.

Plain X-rays were made showing a Mason type II radial head fracture and a Galeazzi type II fracture-dislocation (Figure 1). The patient was admitted to our hospital and open reduction and internal fixation (ORIF) of the radial head were performed through a Kocher approach using two $2.0 \mathrm{~mm}$ cortical screws. By a Henry approach, ORIF of the radius fracture were made with a $3.5 \mathrm{~mm}$ LC-DCP plate and a Kirschner wire to lock the distal radioulnar joint (Figure 2).

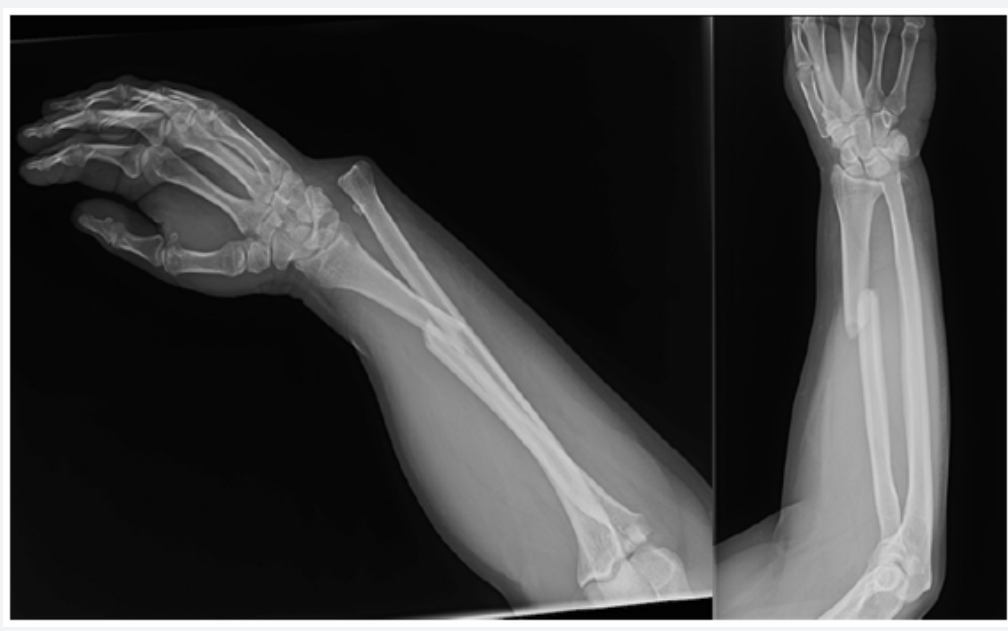

Figure 1: Radiographic exam, showing a type 2 Galeazzi fracture-dislocation and the radial head fracture. 


\section{Orthopedics and Rheumatology Open Access Journal (OROAJ)}

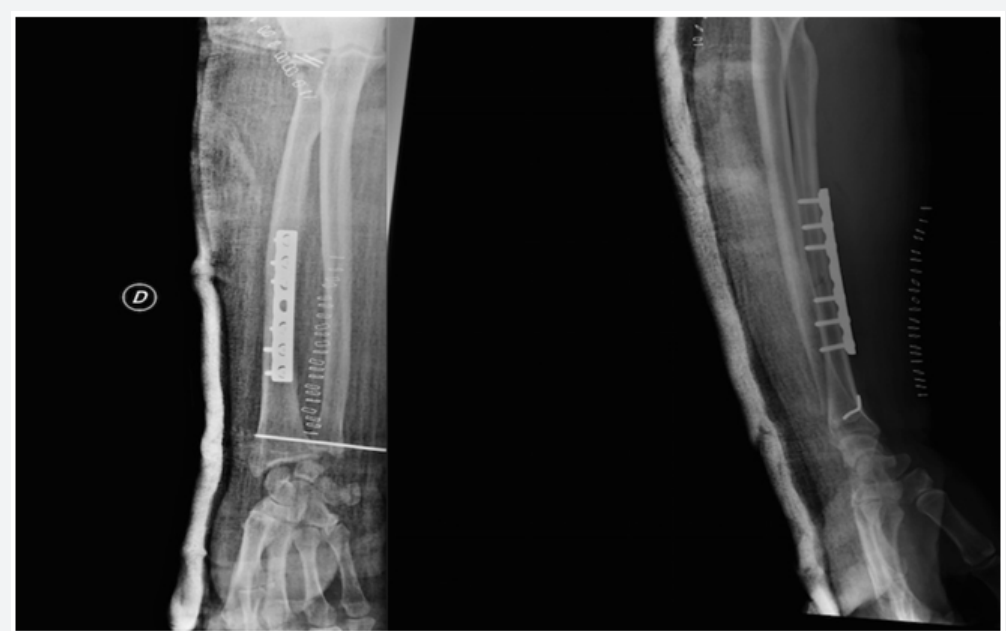

Figure 2: Postoperative radiographic exam.

\section{Results}

No instability of the elbow was found after the fixation or of the radioulnar joint. Finally, the extremity was immobilized with a long-arm posterior splint. The splint and wire were removed following 3 weeks and the patient was sent to physiotherapy.
After 2 month of the patient recovered a range of motion (ROM) of 55 degrees of forearm pronation-supination and 170-30 degrees of elbow flexoextension (Figure 3). Currently, at 6 month of follow-up, the patient is pain free and carries out his daily living activities.

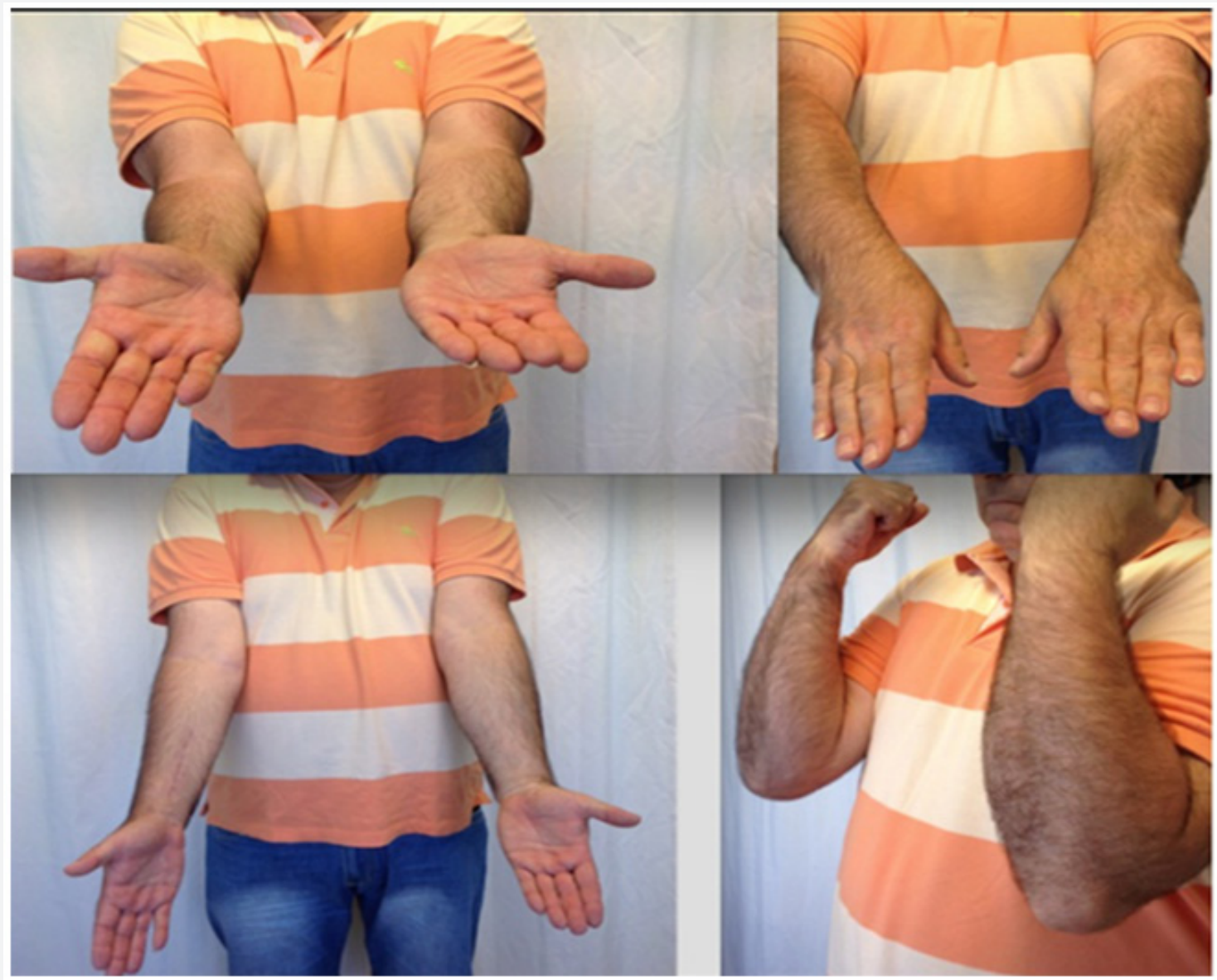

Figure 3: Range of motion of the patient after 2 months of the surgery. 


\section{Discussion}

Galeazzi fracture-dislocation associated to a radial head fracture is an extremely rare injury. Only one case has been reported in literature to our knowledge, describing a man who suffered a height fall and consequently a similar injury to ours, except for a comminuted radial head fracture and a type 1 fracture-dislocation [1]. Thus, ours would be the second lesion reported in literature. Galeazzi fracture-dislocations can be classified in two subtypes of injuries depending on the mechanism: type I fracture, characterized by dorsal displacement of the distal fragment of the radius and volar dislocate of the distal ulna (axial loading of the hypersupinated forearm) and type II fracture which presents volar displacement of the distal radial fragment an a dorsal dislocation of the distal ulna (hyperpronated forearm) [2]. Ours would be a type II Galeazzi fracture-dislocation.

The radial head fracture would be caused by an axial loading over an outstretched wrist, pronated forearm and a valgus force. In this point, if a rotational force is applied which move the arm to a position of supination, a posterolateral rotatory subluxation of the elbow may appear [3]. However, other combinations of Galeazzi fracture-dislocation together with elbow dislocation have been reported [4-9]. In the article published by Asadollahi et al. [10], in which Galeazzi fracture-dislocations concomitantly with elbow dislocations are reported, a mechanism of injury is described. The lesion would be the result of a forceful axial loading of the hyperpronated forearm, a radial shaft failure and consequently the axial loading force would be transmitted only trough the ulna, which finally causes the elbow dislocation. We believe that this could be a logical explanation to the final elbow dislocation in Galeazzi fracture-dislocations.

Our case does not present an elbow dislocation or injury to the ligaments of the elbow because it would be a different mechanism. To assess this issue, we suggest that the lesion would consist of two different consecutive phases. Firstly, based on the mechanism described for the radial head fractures, an axial force is applied with the forearm in hyperpronation, causing the elbow fracture. In this point, there is no rotational force. Hyperpronation position is maintained while still acting the axial load, causing the type 2 Galeazzi fracture-dislocation. The case previously described explained a different mechanism of injury although it was a type 1 fracture-dislocation [1].

\section{Conflict of Interest}

None.

\section{References}

1. Khurana JS, Kattapuram SV, Becker S, Mayo-Smith W (1988) Galeazzi injury with an associated fracture of the radial head. Clin Orthop 234: 70-71.

2. Atesok KI, Jupiter JB, Weiss AP (2011) Galeazzi fracture. J Am Acad Orthop Surg 19: 623-633.

3. King GJ (2007) Radial head fractures. In: Green DP, et al. (Eds), Green's Operative Hand Surgery. Elsevier Inc, New York, USA, pp. 845-887.

4. Shiboi R, Kobayashi M, Watanabe Y, Matsushita T (2005) Elbow dislocation combined with ipsilateral Galeazzi fracture. J Orthop Sci 10(5): 540-542.

5. Ng VY, Rose S (2010) Combined elbow fracture-dislocation and Galeazzi fracture in an adult: a case report and review of the literature. Current Orthopaedic Practice 21(3): 330-333.

6. Nanno M, Sawaizumi T, Takai S (2011) Case of bilateral Galeazzi fractures associated with dislocation of the right elbow. J Nippon Med Sch 78(6): 384-387.

7. Mezzadra A, Gusmeroli E, Tettamanzi M, Prestianni B, Molinari D (1991) A rare injury to the upper limb: elbow dislocation combined with Galeazzi fracture-dislocation. Ital J Orthop Traumatol 17: 567572.

8. Rajeev A, Senevirathna S, Harrison J (2011) Subacute dislocation of the elbow following Galeazzi fracture-dislocation of the radius: a case report. J Med Case Rep 5: 589.

9. Sarup S, Bryant PA (1997) Ipsilateral humeral shaft and Galeazzi fractures with a posterolateral dislocation of the elbow: a variant of the floating dislocated elbow. J Trauma 43(2): 349-352.

10. Asadollahi A, ShepherdD, Hau RC (2013) Elbow fracture-dislocation combined with Galeazzi fracture in adult: A case report and literature review. Int J Surg Case Rep 4(8): 748-752.

\section{Your next submission with Juniper Publishers will reach you the below assets}

- Quality Editorial service

- Swift Peer Review

- Reprints availability

- E-prints Service

- Manuscript Podcast for convenient understanding

- Global attainment for your research

- Manuscript accessibility in different formats

( Pdf, E-pub, Full Text, Audio)

- Unceasing customer service

Track the below URL for one-step submission https://juniperpublishers.com/online-submission.php 